\title{
Japon Bıldırcını Diyetlerine Betain İlavesinin Büyüme Performansı, Karkas ve Duodenum Villus Uzunluğu Üzerine Etkisi
}

\author{
Mükremin ÖLMEZ \\ Kafkas Üniversitesi Veteriner Fakültesi Hayvan Besleme ve Beslenme Hastalıkları ABD, Kars, Türkiye
}

Atıf yapmak için: ÖImez, M. (2021). Japon Bıldırcını Diyetlerine Betain İlavesinin Büyüme Performansı, Karkas ve Duodenum Villus Uzunluğu Üzerine Etkisi. Anadolu Çev. ve Hay. Dergisi, 6(3), 390-394

How to cite: Ölmez, M. (2021). Effects of Betain Using on Growth Performance, Carcass and Duodenum Villus Length in Japanese Quail Diets. J. Anatolian Env. and Anim. Sciences, 6(3), 390-394.

Öz: Bu çalışma bıldırcın diyetlerine ilave edilen betainin performans, karkas randımanı ve bazı iç organ ağırlıkları ile duodenum villus uzunlukları üzerine etkilerini incelemek amacı ile yapılmıştır. Deneme 1 günlük yaştaki 150 adet japon bıldırcını ile yürütülmüştür. Araştırmada hayvanlar 1 kontrol ve 2 deneme grubu olmak üzere toplam 3 gruba ayrılmıştır. Gruplar, her birinde 10 civciv bulunan 5 alt gruba ayrılmıştır. Denemede kontrol grubu sadece bazal diyetle beslenirken deneme gruplarına sırasıyla; $\% 0,3$ ve $\% 0,8$ betain HCL eklenmiştir. Deneme rasyonları izokalorik ve izonitrojenik olarak hazırlanmıştır. Hayvanlara yem ve su ad-libitum verilmiştir. Çalışma 35 gün sürdürülmüştür. Elde edilen verilere göre betainin bıldırcın diyetlerine ilavesiyle canlı ağırlık, canlı ağırlık artışı, yem tüketimi, yemden yararlanma oranı ile duodenum villus uzunluğu üzerine istatistiksel olarak olumlu etkiler gösterdiği belirlenmiştir $(\mathrm{P}<0,05)$. Karkas randımanı ve bazı iç organ ağırlıkları üzerine etkisinin olmadığı tespit edilmiştir $(\mathrm{P}>0,05)$. Sonuç olarak; bıldırcın diyetlerine $\% 0,8$ düzeyinde betain ilavesinin büyüme performansı ve bağırsak sağlığını iyileştirdiği ve güvenle kullanılabileceği sonucuna varılmıştır.

$\underline{\text { Anahtar Kelimeler: Betain,bildırcın, karkas, performans, villus. }}$

\section{Effects of Betain Using on Growth Performance, Carcass and Duodenum Villus Length in Japanese Quail Diets}

*Corresponding author's: Mükremin ÖLMEZ

Division of Animal Nutrition and Nutritional Diseases, Faculty of Veterinary, Kafkas University, KARS, Turkey 囚: mukremin.olmez@hotmail.com

\begin{abstract}
This study was aimed to examine the effects of betaine supplemented to quail diets on performance, carcass yield and some visceral weights and duodenal villus lengths. The study was conducted with 150 one-day-old Japanese quails. In the study, animals were equally divided into 3 groups as 1 control and 2 experimental groups. Groups were divided into 5 subgroups of 10 chicks each. While the control group was fed only basal diet, the experimental groups were fed with; $0.3 \%$ and $0.8 \%$ betaine HCL were added in the trial. Diets were prepared as isocaloric and isonitrogenic. Feed and water were supplied ad-libitum. The study was lasted for 35 days. According to the data obtained, betaine was found to have statistically positive effects on body weight, body weight gain, feed consumption, feed conversion rate and duodenal villus length with the supplementation of quail diets $(\mathrm{P}<0.05)$. It was found that it had no effect on the carcass yield and some visceral weights $(\mathrm{P}>0.05)$. It was concluded that $0.8 \%$ betaine supplementation to quail diets improved growth performance and intestinal health and could be used safely.
\end{abstract}

Keywords: Betaine, carcass, quail, performance, villus. 


\section{GİRiş}

Betain, protein ve enerji metabolizmasında önemli rol oynayan üç metil grubundan oluşan amino asit türevidir (Ratriyanto vd., 2009). Kanatlı organizmasında betain metil donörü ve ozmoprotektan olarak iki önemli fonksiyona sahiptir (Metzler-Zebeli vd., 2009). Bunun yanında betainin sindirim kanalındaki besin maddelerinin sindirilebilirliğini arttırdığı bilinmektedir (Eklund vd., 2006). Betain, kolin ve metiyonin çiftlik hayvanlarının rasyonlarında 3-metil grubu sağlayıcılarıdır. Metiyonin protein sentezinde birincil kaynak olarak kullanılırken geri kalan kısmı metil grubu reaksiyonlarında değerlendirilmektedir (DasSarma vd., 2006). Kolin, asetilkolinin sentezinde kullanıldıktan sonra geri kalanı betain molekülüne dönüştürülmektedir (Niculescu \& Zeisel, 2002). Betain, metiyonin metabolizmasının oluşturduğu homosisteine metil grubu vererek transsülfürasyon ile metiyonin veya sisteine dönüşmesini sağlar. Betain metiyonin dönüşümüyle protein sentezinin artmasını ve böylece kanatlılarda büyüme performansının daha yüksek olmasını sağlayabilmektedir (Rao vd., 2011). Hayvan beslemede karma yemlere betain ilavesinin kolin ve metiyonin ihtiyacını azalttığ 1 , kolin ve metiyonin yararlanabilirliğini arttırdığı belirtilmiştir (Eklund vd., 2005). Kanatlı diyetlerine betain ilavesinin canlı ağırlığı ve yemden yararlanma oranını iyileştirdiği bildirilmekle birlikte Ayrıca mineral emilimini ve kasların su tutma kapasitesini arttırarak canlı ağırlık ve karkas ağırlığını arttırdığı da tespit edilmiştir (Esteve-Garcia \& Mack, 2000).

Betainin hücrede birikmesi, ozmotik dengenin daha az enerji ile kurulmasını sağlamaktadır (Remus, 2001). Betain ozmotik etkisiyle bağırsak epitel hücrelerini koruyarak villus gelişimini desteklediği ve bağırsakta bulunan mikroorganizmaları destekleyerek besin maddelerinin sindirilebilirliğini arttırmaktadır (Dos Santos vd., 2019; Ratriyanto vd., 2017).

$\mathrm{Bu}$ çalışmada Japon bildırcın diyetlerine farklı düzeylerde ilave edilen betainin büyüme performansı, karkas, iç organ ağırlıkları ve duodenum villus uzunlukları üzerine etkilerinin değerlendirilmesi amaçlanmıştır.

\section{MATERYAL VE METOT}

Hayvanlar, Deneme Dizaynı ve Yem: Bu çalışma Kafkas Üniversitesi Hayvan Deneyleri Yerel Etik Kurulu'nun KAÜ-HADYEK/2020-159 kodlu onayıyla yapıldı. Çalışma 35 gün sürdürüldü. Hayvan materyali olarak bir günlük yaşta 150 adet Japon bıldırcını (Coturnix coturnix japonica) kullanıldı. Çalışma 1 kontrol ve 2 deneme olmak üzere üç grupla yürütüldü. Her bir deneme grubu içerisinde on hayvan bulunan beş alt gruba ayrıldı. Araştırmada kontrol grubuna bazal diyet verilirken deneme grubu diyetlerine $\% 0,3$ ve $\% 0,8$ betain HCL ilave edildi. Her alt gruptaki bildırcınlar $60 \times 20 \times 100 \mathrm{~cm}$ ölçülerine sahip türe özel olarak düzenlenmiş kafeslerde barındırıldı. Çalışmadaki tüm gruplar \%24 HP ve $2950 \mathrm{kcal} / \mathrm{kg} \mathrm{ME}$ içeren diyetle beslendi (Tablo 1). Diyet formülasyonu NRC'ye göre hazırlandı (Dale, 1994) ve AOAC'ye göre besin madde analizleri yapıldı (AOAC, 2019). Hayvanlara yem ve su ad libitum olarak sunuldu. Çalışma süresince tüm hayvanlar ilk üç gün boyunca $32-33{ }^{\circ} \mathrm{C}$ sicaklıkta tutulduktan sonra sicaklık her hafta $1-2{ }^{\circ} \mathrm{C}$ düşürülerek 25 ${ }^{\circ} \mathrm{C}$ 'ye sabitlendi. Kafeslere 24 saat/gün aydınlatma sağlandı. Araştırmada kullanılan betain özel bir ticari firmadan (Betamar ${ }^{\circledR}$, Vimar A.Ş.- İstanbul) tedarik edildi.

Tablo 1. Beslemede kullanılan rasyonun besin madde ve kimyasal analiz içeriği.

Table 1. Nutrient and chemical analysis content of the diet.

\begin{tabular}{|c|c|}
\hline İçindekiler & $\%$ \\
\hline Misir & 56,11 \\
\hline Soya küspesi (\%48 HP) & 40,20 \\
\hline Bitkisel yağ & 1,00 \\
\hline Mermer tozu & 1,33 \\
\hline Dikalsiyum fosfat & 0,60 \\
\hline Tuz & 0,25 \\
\hline L-lizin sülfat & 0,15 \\
\hline L-treonin & 0,11 \\
\hline Vitamin - Mineral karışım1 ${ }^{1}$ & 0,25 \\
\hline Toplam & 100 \\
\hline \multicolumn{2}{|l|}{ Besin madde analizi } \\
\hline Ham protein $(\%)$ & 23,80 \\
\hline *Metabolize enerji (Kcal/kg) & 2950 \\
\hline *Kalsiyum (\%) & 1,19 \\
\hline *Fosfor $(\%)$ & 0,31 \\
\hline$*$ Lizin $(\%)$ & 1,33 \\
\hline *Metiyonin (\%) & 0,80 \\
\hline$*$ Treonin $(\%)$ & 1,02 \\
\hline *Triptofan (\%) & 0,33 \\
\hline
\end{tabular}

Performans: Canlı ağırlık (CA) ve yem tüketimi (YT) tüm alt gruplarda haftalık olarak belirlendi. Yapılan tartımlar sonucu elde edilen farklardan canlı ağırlık artışı (CAA) ve yemden yararlanma oranı (YYO) hesaplandı (YT/CAA).

Karkas Parametreleri: Denemenin sonunda, karkas özelliklerini incelemek için her gruptan rastgele 10 adet bıldırcın seçilip aç bırakıldıktan sonra tek tek tartılıp kesim ağırlıkları belirlenerek kesildi. Kesilen hayvanların kanı boşaltıldıktan sonra tüyler yolundu. İç organlar (kalp, karaciğer ve taşlık) çıkarılarak karkas ve iç organları tartılıp ağırlıkları belirlendi. Sıcak karkas randımanı hesaplandi.

Histolojik Analizler: Çalışma sonunda bıldırcanlardan alınan duodenum doku örnekleri \%10’luk formol solüsyonunda tespit edildikten sonra rutin histolojik işlemlerden geçirilerek parafinde bloklandı. Bu bloklardan alınan $5 \mu$ 'luk kesitlere duodenum dokusunun genel yapısını incelemek amacı ile Crossman'ın üçlü boyama tekniği (Triple Boyama) uygulandı (Luna, 1968). Tüm grupların duodenum dokusunda villus uzunluk ölçümleri için image-j (vI. 50i) software programı kullanıldı. Villus uzunluk ölçümleri her bir grupta 4 farklı kesitteki toplam 
40 alandan yapıldı (Akgül vd., 2015).

İstatistik Analiz: Elde edilen performans ve karkas parametreleri ile villus uzunlukları SPSS 20.0 (IBM-USA) istatistik programında değerlendirildi. Gruplara ait sonuçlar arasındaki farklılık tek yönlü varyans analizi (ANOVA) ile belirlendi. Gruplar arasındaki ikili karşılaştırmalarda Duncan çoklu karşılaştırma testi kullanıldı. Önemlilik $\mathrm{P}<0,05$ derecesinde belirlendi.

\section{BULGULAR}

Bildırcin diyetlerine betain ilavesinin performans üzerine etkileri Tablo 2' de verilmiştir. Deneme sonu CA, CAA, YT ve YYO betain içeren gruplarda istatistik olarak önemli derecede etkilenmiştir $(\mathrm{P}<0,05)$.

Tablo 2. Betainin performans parametreleri üzerine etkisi Table 2. Effect of betaine on performance parameters

\begin{tabular}{|c|c|c|c|c|}
\hline Parametreler & Kontrol & B1 & B2 & $\mathbf{P}$ \\
\hline Çıkım, g & $8,30 \pm 0,02$ & $8,29 \pm 0,02$ & $8,28 \pm 0,03$ & 0,833 \\
\hline CA-35.gün, $g$ & $172,29 \pm 0,77^{\mathrm{b}}$ & $180,27 \pm 1,08^{\mathrm{a}}$ & $179,20 \pm 1,28^{\mathrm{a}}$ & 0,001 \\
\hline CAA, g/gün & $4,69 \pm 0,02^{\mathrm{b}}$ & $4,91 \pm 0,03^{\mathrm{a}}$ & $4,88 \pm 0,04^{\mathrm{a}}$ & 0,001 \\
\hline YT, g/gün & $16,45 \pm 0,11^{\mathrm{b}}$ & $17,07 \pm 0,11^{\mathrm{a}}$ & $16,79 \pm 0,15^{\mathrm{ab}}$ & 0,009 \\
\hline YYO, $\mathbf{g} / \mathbf{g}$ & $3,51 \pm 0,03^{\mathrm{b}}$ & $3,48 \pm 0,00^{\mathrm{ab}}$ & $3,44 \pm 0,00^{\mathrm{a}}$ & 0,016 \\
\hline
\end{tabular}

Çalışma sonuçlarına göre karkas randımanı, kalp, karaciğer ve taşlık ağırlıkları betain ilavesinden etkilenmemiştir $(\mathrm{P}>0,05)$ (Tablo 3).

Tablo 3. Betainin kesim parametreleri üzerine etkisi

Table 3. Effect of betaine on slaughter parameters

\begin{tabular}{lcccc}
\hline Parametreler & Kontrol & $\mathbf{0 , 3 \%}$ Betain & $\mathbf{0 , 8 \%}$ Betain & P \\
\hline Karkas Randımanı, \% & $64,28 \pm 1,99$ & $65,01 \pm 2,68$ & $67,12 \pm 1,86$ & 0,647 \\
Kalp, g & $1,66 \pm 0,07$ & $1,52 \pm 0,04$ & $1,51 \pm 0,08$ & 0,716 \\
Karaciğer, g & $4,53 \pm 0,33$ & $4,22 \pm 0,29$ & $4,34 \pm 0,17$ & 0,409 \\
Taşlık, g & $2,93 \pm 0,38$ & $3,18 \pm 0,20$ & $3,44 \pm 0,15$ & 0,507 \\
\hline
\end{tabular}

Histolojik parametreler incelendiğinde $\% 0,8$ düzeyinde betain HCL ilave edilen grupta duodenum villus uzunluğunun diğer gruplara göre daha yüksek olduğu tespit edilmiştir $(\mathrm{P}<0,05)$ (Tablo 4).

Tablo 4. Betainin duodenum villus uzunluğu üzerine etkisi Table 4. Effect of betaine on duodenal villus length \begin{tabular}{lcccc}
\hline Parametre & Kontrol & $\mathbf{0 , 3 \%}$ Betain & $\mathbf{0 , 8 \%}$ Betain & P \\
\hline Villus uzunluğu $(\boldsymbol{\mu m})$ & $1309,60 \pm 53,25^{\mathrm{b}}$ & $1214,09 \pm 59,68^{\mathrm{b}}$ & $1640,58 \pm 76,98^{\mathrm{a}}$ & 0,001
\end{tabular} a,b: Aynı satırda farklı harflerle ifade edilen ortalamalar arasındaki farklılıklar önemlidir $(\mathrm{P}<0,05)$.

\section{TARTIŞMA VE SONUÇ}

$\mathrm{Bu}$ araştırma bıldırcın diyetlerine ilave edilen betain katkısının CA, CAA, YT, YYO, karkas randımanı ve iç organ ağırlıkları ile duodenum villus uzunlukları üzerine olan etkilerini tespit etmek amaciyla yürütülmüştür.

Betain ilavesinin çalışma sonunda performans parametrelerini istatistik olarak önemli derecede iyileştirdiği bulunmuştur. Deneme sonu CA ve ortalama günlük CAA incelendiğinde betain ilave edilen iki grupta da kontrol grubuna göre daha yüksek canlı ağırlık değerleri elde edilmiştir. Günlük ortalama en yüksek YT'nin \%0,3 betain HCL içeren grupta olduğu belirlenirken en iyi YYO' nun ise \%0,8 betain HCL içeren grupta olduğu tespit edilmiştir.

Sunulan

çalışmanın

sonuçları değerlendirildiğinde bazı çalışmalarla uyum içerisinde olduğu görülmüştür. Betainin etlik piliçlerde performans parametrelerinin değerlendirildiği bir çalışmada diyete $\% 0.8$ düzeyinde ilavesinin $\mathrm{CA}$ ve $\mathrm{CAA}^{\prime} \mathrm{y} 1$ arttırdı $\mathrm{g} 1$ bildirilmiştir (Şahin vd., 2020). Chand vd., (2017) ise etlik piliç diyetlerine betainin $2 \mathrm{~g} / \mathrm{kg}$ düzeyinde ilavesi ile $Y T$ ve YYO'yu olumlu düzeyde etkilendiğini belirtmişlerdir. ElHusseiny, (2007) de broiler diyetlerine $0.75 \mathrm{~g} / \mathrm{kg}$ düzeyinde betain ilavesinin YYO'yu iyileştirdiğini belirlemiştir. Mevcut çalışma sonuçları diğer bazı literatür bildirişleriyle de benzerlik göstermiştir (Liu vd., 2019; Sakomura vd., 2013b). Araştırmalardan elde edilen performans parametrelerinde görülen iyileşmenin betainin etkisiyle artan besin madde sindiriminden kaynaklanabileceği ifade edilmiştir (Sakomura vd., 2013b). Yine betainin enerji ve protein metabolizmasını etkileyerek büyüme performansını destekleyebileceği tespit edilmiştir (Eklund vd., 2005).

Waldroup vd., (2006)'nin betain ilavesiyle performans parametrelerinde herhangi bir değişiklik olmadığı yönündeki bildirişi ile Schutte vd., (1997)'nin betainin etlik piliçlerde performansı düşürdüğü yönündeki bildirişi mevcut çalışma sonuçları ile farklılık arz etmiştir. Betainin etkinliğinde görülen farklılıkların rasyonların protein ve enerji içeriğine bağlı olabileceği bildirilmiştir (Lawrence vd., 2002).

Yapılan araştırmalarda betain ilavesinin karkas randımanı ile kalp, karaciğer ve taşlık ağırlıkları üzerine etkisinin olmadığını bildiren sonuçlar mevcut çalışma sonuçları ile benzerlik göstermektedir (El-Shinnawy, 2015; Şahin vd., 2020). Benzer şekilde Uzunoğlu ve Yalcin, (2019) betain ilavesinin etlik piliçlerde karkas randımanını etkilemediğini bildirmişlerdir. $\mathrm{Bu}$ çalışmaların aksine betain ilavesinin su tutma kapasitesini artırarak, karkas randımanını yükselttiği yönünde araştırma sonuçları da bulunmaktadır (Chand vd., 2017; Waldroup \& Fritts, 2005). Başka bir çalışmada ise etlik piliçlerde betain ilavesinin karkas randımanını arttırdığı, ancak karaciğer üzerine olumsuz etki gösterdiği belirlenmiştir (Jahanian \& Rahmani, 2008). Etlik piliçlerde yapılan bir çalışmada ise betainin $100 \mathrm{mg} / \mathrm{kg}$ düzeyinde ilavesinin karkas randımanı üzerine iyileştirici etki gösterdiği tespit edilmiştir (Esteve-Garcia \& Mack, 2000). Sonuçlarda görülen farklılıkların beslenme şartlarıyla birlikte betainin kullanım dozu ile ilişkili olduğu düşünülmektedir.

Bağırsaklarda görülebilecek bozukluklar veya 
hasarlar besinlerin emiliminin azalmasina, epitel geçirgenliğinin artmasına, hastalıklara karşı direncin azalmasina ve bunun sonucunda da kanatllarda performansın düşmesine yol açmaktadır (Wijtten vd., 2011). Bu açıdan bakıldığında bağırsak morfolojisi genel anlamda bağırsak sağlığı hakkında araştırmalara $1 s ̧ ı k$ tutabilmektedir. Bağırsak villus bütünlüğünün ve epitel hücrelerinin aktivitesinin korunmas1 patojen mikroorganizmaların girişini önleyeceğinden bağırsak sağlığının iyileştirilmesinde önemli rol oynamaktadır (Wang vd., 2020). Nitekim mevcut çalışmada, betain ilavesinin duodenum villus uzunluğunu arttırdığı belirlenmiştir. Bağırsaklarda betain birikimi, enterositlerin su tutma kapasitesini geliştirdiğinden bağırsak epitel hücrelerinin yapısının korunmasında etkili olduğu ve kanatlılarda bağırsağın gerilme mukavemetini artırarak villus uzunluğunu olumlu etkilediği ortaya konmuştur (Kettunen vd., 2001a). Betaninin bu sayede kanatllarda besin emilimini ve yemden yararlanma oranını arttrarak performansı iyileştirdiği düşünülmektedir. Dos Santos vd., (2019) etlik piliçlerde betain ilavesinin, duodenum villus genişliğini azaltıp, uzunluğunu artırdığını bunun da duodenumda emilim kapasitesini iyileştirdiğini bildirmişlerdir. Başka bir çalışmada ise betainin iyonofor antikoksidiyallerle birlikte kullanımının bağırsak sağlığını koruduğu belirtilmiştir (Kettunen vd., 2001b). Eklund vd., (2005) betainin etlik piliçlerde bağırsak villus bütünlüğünü koruyarak daha iyi besin emilimi ve sindirilebilirlik sağladığını tespit etmişlerdir. Betainin 1Sı stresi altındaki etlik piliçlerde villus uzunluğunu etkilemediğini bildiren çalışmalar da bulunmaktadır (Sakomura vd., 2013a). Ortaya çıkan bu farklılığın oluşturulan 1sı stresinin boyutu ve süresi ile diyete katılan betain düzeyine bağlı olabileceğini düşündürmüştür.

Sonuç olarak; betain $\% 0,8$ düzeyinde canlı ağırlık, canlı ağırlık artıșı, yemden yararlanma oranı ve duodenum villus uzunluğunu iyileștirmiștir. Kanatlı diyetlerine betain ilavesinin bağırsak sağlığını olumlu etkileyerek performansı artırabileceği ancak kesim parametrelerini artırıcı etkinliğinin araştırılması gerektiği kanaatine varılmıştır.

\section{TEŞEKKÜR}

Çalışmanın histolojik analizleri için Dr. Öğr. Üyesi Şükran YEDİEL ARAS'a teşekkür ederiz.

\section{KAYNAKLAR}

Akgül, C., Özparlak, H., Çelİk, İ. \& Öznurlu, Y. (2015). Nifedipinin ince bağırsak histolojisi üzerine etkileri. Research Journal of Biology Sciences, 8(1), 11-18.
AOAC. (2019). Official methods of analysis 21st ed., Association of Official Analytical Chemists, Washington, DC.

Chand, N., Naz, S., Maris, H., Khan, R.U., Khan, S. \& Qureshi, M.S. (2017). Effect of betaine supplementation on the performance and immune response of heat stressed broilers. Pakistan Journal of Zoology, 49(5), 1857-1862. DOI: 10.17582/journal.pjz/2017.49.5.1857.1862

Chand, N., Naz, S., Maris, H., Khan, R.U., Khan, S. \& Qureshi, M.S. (2017). Effect of betaine supplementation on the performance and immune response of heat stressed broilers. Pakistan Journal of Zoology, 49(5), 1857-1862. DOI: 10.17582/journal.pjz/2017.49.5.1857.1862

Dale, N. (1994). National research council nutrient requirements of poultry-ninth revised edition (1994). Journal of Applied Poultry Research, 3(1), 101

DasSarma, S., Berquist, B.R., Coker, J.A., DasSarma, P. \& Müller, J.A. (2006). Post-genomics of the model haloarchaeon Halobacterium sp. NRC-1. Saline Systems, 2(1), 1-12. DOI: 10.1186/17461448-2-3

Dos Santos, T.T., Dassi, S.C., Franco, C.R., da Costa, C.R., Lee, S.A. \& da Silva, A.V.F. (2019). Influence of fibre and betaine on development of the gastrointestinal tract of broilers between hatch and $14 \mathrm{~d}$ of age. Animal Nutrition, 5(2), 163-173. DOI: 10.1016/j.aninu.2018.06.005

Eklund, M., Bauer, E., Wamatu, J. \& Mosenthin, R. (2005). Potential nutritional and physiological functions of betaine in livestock. Nutrition Research Reviews, 18(1), 31-48. DOI: 10.1079/NRR200493

Eklund, M., Mosenthin, R., Tafaj, M. \& Wamatu, J. (2006). Effects of betaine and condensed molasses solubles on nitrogen balance and nutrient digestibility in piglets fed diets deficient in methionine and low in compatible osmolytes. Archives of Animal Nutrition, 60(4), 289-300. DOI: $10.1080 / 17450390600785525$

El-Husseiny, O. (2007). Response of broilers performance to dietary betaine and folic acid at different methionine levels. International Journal of Poultry Science, 6(7), 515-523. DOI: 10.3923/ijps.2007.515.523

El-Shinnawy, A. (2015). Effect of betaine supplementation to methionine adequate diet on growth performance, carcass characteristics, some blood parameters and economic efficiency of broilers. Journal of Animal and Poultry Production, $\quad$ 6(1), 27-41. DOI: 10.21608/jappmu.2016.52726

Esteve-Garcia, E. \& Mack, S. (2000). The effect of DLmethionine and betaine on growth performance and carcass characteristics in broilers. Animal Feed Science and Technology, 87(1-2), 85-93. DOI: $10.1016 / \mathrm{S} 0377-8401(00) 00174-7$

Jahanian, R. \& Rahmani, H. (2008). The effect of dietary fat level on the response of broiler chicks to 
betaine and choline supplements. Journal of Biological Sciences, 8(2), 362-367. DOI: 10.3923/jbs.2008.362.367

Kettunen, H., Peuranen, S. \& Tiihonen, K. (2001a). Betaine aids in the osmoregulation of duodenal epithelium of broiler chicks, and affects the movement of water across the small intestinal epithelium in vitro. Comparative Biochemistry and Physiology Part A: Molecular \& Integrative Physiology, 129(2), 595-603. DOI: 10.1016/S1095-6433(01)00298-7

Kettunen, H., Tiihonen, K., Peuranen, S., Saarinen, M. \& Remus, J. (2001b). Dietary betaine accumulates in the liver and intestinal tissue and stabilizes the intestinal epithelial structure in healthy and coccidia-infected broiler chicks. Comparative Biochemistry and Physiology Part A: Molecular \& Integrative Physiology, 130(4), 759-769. DOI: 10.1016/s1095-6433(01)00410-x

Lawrence, B., Schinckel, A., Adeola, O. \& Cera, K. (2002). Impact of betaine on pig finishing performance and carcass composition. Journal of animal science, $80(2), \quad 475-482 . \quad$ DOI: $10.2527 / 2002.802475 \mathrm{x}$

Liu, W., Yuan, Y., Sun, C., Balasubramanian, B., Zhao, Z. \& An, L. (2019). Effects of dietary betaine on growth performance, digestive function, carcass traits, and meat quality in indigenous yellowfeathered broilers under long-term heat stress. Animals, 9(8), 506. DOI: 10.3390/ani9080506

Luna, L.G. (1968). Manual of histologic staining methods of the Armed Forces Institute of Pathology 3rd ed., Blakiston Division, McGraw-Hill, New York.

Metzler-Zebeli, B., Eklund, M. \& Mosenthin, R. (2009). Impact of osmoregulatory and methyl donor functions of betaine on intestinal health and performance in poultry. World's Poultry Science Journal, $\quad \mathbf{6 5}(3), \quad$ 419-442. $\quad$ DOI: 10.1017/S0043933909000300

Niculescu, M.D. \& Zeisel, S.H. (2002). Diet, methyl donors and DNA methylation: interactions between dietary folate, methionine and choline. The Journal of nutrition, 132(8), 2333S-2335S. DOI: $10.1093 / \mathrm{jn} / 132.8 .2333 \mathrm{~S}$

Rao, S.V., Raju, M.V.L.N., Panda, A.K., Saharia, P. \& Sunder, G.S. (2011). Effect of supplementing betaine on performance, carcass traits and immune responses in broiler chicken fed diets containing different concentrations of methionine. Asian-Australasian Journal of Animal Sciences, 24(5), 662-669. DOI: 10.5713/ajas.2011.10286

Ratriyanto, A., Indreswari, R. \& Nuhriawangsa, A.M.P. (2017). Effects of dietary protein level and betaine supplementation on nutrient digestibility and performance of Japanese quails. Brazilian Journal of Poultry Science, 19(3), 445454. DOI: 10.1590/1806-9061-2016-0442

Ratriyanto, A., Mosenthin, R., Bauer, E. \& Eklund, M. (2009). Metabolic, osmoregulatory and nutritional functions of betaine in monogastric animals. Asian-Australasian Journal of Animal Sciences, 22(10), 1461-1476. DOI: 10.5713/ajas.2009.80659

Remus, J. (2001). Betaine for increased breast meat yield in turkeys. Poultry World, 21(2), 14-15.

Sakomura, N., Barbosa, N., Longo, F., Da Silva, E., Bonato, M. \& Fernandes, J. (2013a). Effect of dietary betaine supplementation on the performance, carcass yield, and intestinal morphometrics of broilers submitted to heat stress. Brazilian Journal of Poultry Science, 15(2), 105-112. DOI: 10.1590/S1516635X2013000200005

Sakomura, N.K., Barbosa, N.A., Da Silva, E.P., Longo, F.A., Kawauchi, I.M. \& Fernandes, J.B. (2013b). Efeito da suplementação de betaína em dietas de frangos de corte em condições de termoneutralidade. Revista Brasileira de Ciências Agrárias, $\quad \mathbf{8}(2), \quad 336-341 . \quad$ DOI: 10.5039/agraria.v8i2a1442

Schutte, J., De Jong, J., Smink, W. \& Pack, M. (1997). Replacement value of betaine for DL-methionine in male broiler chicks. Poultry Science, 76(2), 321-325. DOI: $10.1093 / \mathrm{ps} / 76.2 .321$

Şahin, T., Özel, O.Ç. \& Ölmez, M. (2020). The Effect of Supplementation of Betaine on Performance, Carcass Yield and Some Blood Parameters in Broilers. Erciyes Üniversitesi Veteriner Fakültesi Dergisi, 17(3), 260-267. DOI: 10.32707/ercivet.828789

Uzunoğlu, K. \& Yalcin, S. (2019). Effects of dietary supplementation of betaine and sepiolite supplementation on performance and intestinal health in broilers. Ankara Üniversitesi Veteriner Fakültesi Dergisi, $\quad \mathbf{6 6}(3), \quad 221-230 . \quad$ DOI: 10.33988/auvfd.434359

Waldroup, P., Motl, M., Yan, F. \& Fritts, C. (2006). Effects of betaine and choline on response to methionine supplementation to broiler diets formulated to industry standards. Journal of Applied Poultry Research, 15(1), 58-71. DOI: 10.1093/japr/15.1.58

Waldroup, P.W. \& Fritts, C.A. (2005). Evaluation of Separate and Combined Effects of Choline and Betaine in Diets for Male Broilers. International Journal of Poultry Science, 4(7), 442-448. DOI: 10.3923/ijps.2005.442.448

Wang, H., Li, S., Xu, S. \& Feng, J. (2020). Betaine improves growth performance by increasing digestive enzymes activities, and enhancing intestinal structure of weaned piglets. Animal Feed Science and Technology, 267, 114545. DOI: 10.1016/j.anifeedsci.2020.114545

Wijtten, P.J.A., Meulen, J.V.D. \& Verstegen, M.W.A. (2011). Intestinal barrier function and absorption in pigs after weaning: A review. British Journal of Nutrition, 105(7), 967-981. DOI: $10.1017 / \mathrm{S} 0007114510005660$ 